\title{
Individual Differences in Statistical Learning Predict Children's Comprehension of Syntax
}

\author{
Evan Kidd \\ The Australian National University and ARC Centre of \\ Excellence for the Dynamics of Language
}

\author{
Joanne Arciuli \\ The University of Sydney
}

\begin{abstract}
Variability in children's language acquisition is likely due to a number of cognitive and social variables. The current study investigated whether individual differences in statistical learning (SL), which has been implicated in language acquisition, independently predicted 6- to 8-year-old's comprehension of syntax. Sixty-eight $(N=68)$ English-speaking children completed a test of comprehension of four syntactic structures, a test of SL utilizing nonlinguistic visual stimuli, and several additional control measures. The results revealed that SL independently predicted comprehension of two syntactic structures that show considerable variability in this age range: passives and object relative clauses. These data suggest that individual differences in children's capacity for SL are associated with the acquisition of the syntax of natural languages.
\end{abstract}

Statistical learning (SL), the process of using probability of co-occurrence to group elements in the environment, has long been linked to language acquisition. Artificial language learning (ALL) studies demonstrate that infants and children attend to statistical regularities to help them learn about linguistic systems. For instance, in their seminal study, Saffran, Aslin, and Newport (1996) reported that 8-month-olds use transitional probabilities to segment continuous speech. Smith and $\mathrm{Yu}$ (2008) showed that 12-month-olds can use crosssituational statistics to learn word-referent relations. At the grammatical level, Wonnacott (2011) showed that 6-year-old children use distributional statistics to strike a balance between generalization and lexical conservatism when learning a novel grammatical construction (see also Wonnacott, Boyd, Thomson, \& Goldberg, 2012; for reviews of SL literature, see Arciuli \& von Koss Torkildsen, 2012; Romberg \& Saffran, 2010).

The success of the ALL research suggests that language acquisition may be supported, at least in part, by a mechanism that identifies regularities in input and uses this information to form

This study was supported by a Near Miss Grant awarded to Evan Kidd by The Australian National University, and CE140100041 (CI: Evan Kidd), awarded by the Australian Research Council. Joanne Arciuli's time on this research was supported by an Australian Research Council Future Fellowship (FT130101570). We thank Lauren Morrison for her work testing the children, and all the children and schools who participated.

Correspondence concerning this article should be addressed to Evan Kidd, Research School of Psychology, The Australian National University, Building 39, Acton, Canberra, ACT 2601, Australia. Electronic mail may be sent to evan.kidd@anu.edu.au. generalizations. A complementary line of research has identified individual differences in SL and linked them to individual differences in children's acquisition of natural language "in the wild." This newer line of research parallels similar work on language proficiency in adults (e.g., Christiansen, Conway, \& Onnis, 2012; Conway, Bauernschmidt, Huang, \& Pisoni, 2010; Misyak \& Christiansen, 2012; Misyak, Christiansen, \& Tomblin, 2010), and aims to provide evidence that SL has a role to play in supporting language acquisition at the level of the individual. The current study follows this strategy. Specifically, our goal was to investigate whether individual differences in a (nonlinguistic visual) SL task predicted individual differences in typically developing children's comprehension of different types of syntactic structures.

Recent research demonstrates that the capacity for SL varies between individuals. For example, Kaufman et al. (2010) reported variability in visual sequence learning among healthy 16- to 17-yearolds. Similarly, Arciuli and Simpson (2011) reported individual differences in visual sequence learning of nonlinguistic stimuli in children aged 5-12 years. These individual differences are associated with variation in language proficiency. For instance, several studies have shown that individuals with specific language impairment perform poorly on

(C) 2015 The Authors

Child Development (c) 2015 Society for Research in Child Development, Inc. All rights reserved. 0009-3920/2016/8701-0016

DOI: $10.1111 /$ cdev.12461 
tasks measuring SL in comparison to typically developing controls (Evans, Saffran, \& Robe-Torres, 2009; Lum, Conti-Ramsden, Page, \& Ullman, 2012; Tomblin, Mainela-Arnold, \& Zhang, 2007).

Studies with typically developing children have reported direct correlations between measures of SL and language acquisition. Shafto, Conway, Field, and Houston (2012) showed that individual differences in visual sequence learning of nonlinguistic stimuli in 8.5-month-old infants predicted word comprehension at the same age, as measured by parental report, but did not find a significant longitudinal association with vocabulary at 13.5 months. In contrast, Ellis, Robledo, and Deák (2014) reported a longitudinal association between a similar visual sequence learning task at 6 months and productive vocabulary at 22 months, an association that could not be explained by general cognitive ability as measured by the Bailey Scales of Infant Development. These data provide evidence that individual capacities for SL may assist language acquisition, supporting previous infant studies that have demonstrated the relation at the group level (e.g., Hay, Pelucchi, Graf Estes, \& Saffran, 2011; Lany \& Saffran, 2010; Smith \& Yu, 2008).

The idea that SL supports the acquisition of grammar is controversial, given significant debate regarding the degree to which grammatical acquisition, in particular, depends on domain-specific versus domain-general learning mechanisms (e.g., Chomsky, 2011; Newport, 2011; Perruchet \& Poulin-Charronnat, 2015). Individual differences in SL have been linked to grammatical development, although the current evidence base is small. Lany (2014) reported that 22-month-old infants' ability to learn novel probabilistic word-referent mappings was mediated by their grammatical knowledge, as measured by parental report. Kidd (2012) reported that visual SL predicted children's production of the passive structure in a syntactic priming task in 4- to 6-year-old children. More mixed evidence comes from studies that have used standardized language measures as outcome variables. Although some studies have reported positive associations (Conway, Pisoni, Anaya, Karpicke, \& Henning, 2011; Lum et al., 2012), a recent large study of 553 typically developing children aged 4-10 years by Spencer, Kaschak, Jones, and Lonigan (2015) reported no significant SL-grammar link after controlling for age.

In the current study, we sought to increase the evidence base for the SL-grammar link in 6- to 8year-old typically developing children acquiring English as a first language. Unlike past studies that have either tested children on one structure (Kidd, 2012) or on standardized assessments that provide only broad measures of grammatical knowledge, children's comprehension of four specific syntactic structures was tested, in addition to assessment of $\mathrm{SL}$, verbal working memory (WM), and verbal and nonverbal ability.

Associations between SL and grammar have been reported using both auditory and visual SL tasks (e.g., in children: Lany, 2014; Kidd, 2012; in adults: Conway et al., 2010; Misyak et al., 2010), suggesting that a domain-general capacity for SL supports acquisition and processing. We chose a nonlinguistic visual test of SL that has been shown to elicit variability in children (Arciuli \& Simpson, 2011) and has revealed a link between SL and language proficiency (Arciuli \& Simpson, 2012). A recent study of adults that compared various types of SL tasks reported that a nonlinguistic visual SL task similar to the one used in the present study elicited between-participant variability while retaining good test-retest reliability (Siegelman \& Frost, 2015), which are both essential to identify reliable individual differences.

The language comprehension task that we developed assessed children's knowledge of four different types of structures that describe transitive causal events: (a) simple actives (e.g., the girl is pushing the boy), (b) passives (e.g., the boy is being pushed by the girl), (c) subject relative clauses (RCs; the girl that is pushing the boy), and (d) object RCs (e.g., the boy that the girl is pushing). These structures were chosen because they differ in their formal complexity and frequency of use. Simple actives and subject RCs are acquired fairly early (e.g., Diessel \& Tomasello, 2000; Gertner, Fisher, \& Eisengart, 2006), owing to the fact that they follow English canonical subjectverb-object (SVO) word order. In contrast, both passive and object RCs deviate from SVO word order and are comparatively infrequent. Full BE passives comprise $<1 \%$ of verb forms in spoken English (Xiao, McEnery, \& Qian, 2006); object RCs are similarly rare in spoken language, especially when they occur with animate head nouns as full lexical noun phrases, as in our materials (e.g., the lawyer that the judge reprimanded; see Kidd, Brandt, Lieven, \& Tomasello, 2007). Consequently, even elementary school-aged children, our target population, show marked variability in their comprehension of these forms (Boyle, Lindell, \& Kidd, 2013).

We hypothesized that part of the variability observed in our language comprehension task would be related to individual differences in our nonlinguistic visual SL task. Specifically, we 
investigated the possibility that one reason for variability in grammatical knowledge of low-frequency structures such as passives and object RCs is that distributional cues to acquiring these structures are weak and that a comparatively good domain-general ability for SL facilitates the identification of these cues. We therefore predicted that individual differences in SL would independently predict children's knowledge of passives and object RCs, in particular, even when other linguistic and cognitive variables were taken into account.

\section{Method \\ Participants}

Sixty-eight $(N=68,33$ females $)$ children were recruited from elementary schools in Canberra, Australia. The children had a mean age of $7 ; 1$ years $(S D=5.7$ months, range $=6 ; 1-8 ; 1)$. Consistent with the demographics of the city, the children were from middle- and middle-upper-class socioeconomic backgrounds. They were predominately European Australians in ethnicity (97\%), all were acquiring English as a native language, and they were not reported to have any language or cognitive impairments. The data were collected between June and November 2014.

\section{Materials and Procedure}

The children were tested on a battery of five measures; each is described in turn.

\section{Language Comprehension Task}

A picture pointing task was used. One test item is shown in Figure 1, which depicts two scenes where the same two characters (a chicken and a mouse) are engaging in the same action, but where the role of agent and patient is reversed across pictures (i.e., left: chicken kisses mouse; right: mouse kisses chicken). A total of 128 sentences were distributed across eight lists (for sentences, see online Supporting Information). Each list contained eight sentences of each sentence type, and so children were individually tested on 32 items in total. An error in the construction of the active and passive sentences across lists meant that, overall, there were 28 passive items, but 36 actives. Our analyses controlled for this asymmetry, which did not have an effect on the results. The sentences were generated from a pool of 28 animate characters (depicting humans and animals) and eight transitive verbs (comb, feed, follow, hug, kiss, push, scare, and splash). The verbs and nouns were common and known to children of this age. The target structures were embedded within questions. Relative clause structures were fronted by where (e.g., where is the mouse that is kissing the chicken?); active and passive were fronted by which (e.g., which mouse is being kissed by the chicken?). Both were used in order to focus the first noun in the sentence (i.e., the correct referent). The verbs were in the present progressive because the pictures denoted events that were currently occurring. The test sentences were controlled for length in syllables; all were between 10 and 12 syllables in length (mean length $=10.8$ syllables). All contained two animate nouns. The length of active sentences, which are typically shorter than the other three sentence types because they require less grammatical function words (e.g., is being, that), was made longer using adjectives that did not provide any clues to the identity of the target referent (e.g., nice, tall).

For each trial, the experimenter showed the child the two reversible pictures and read out one
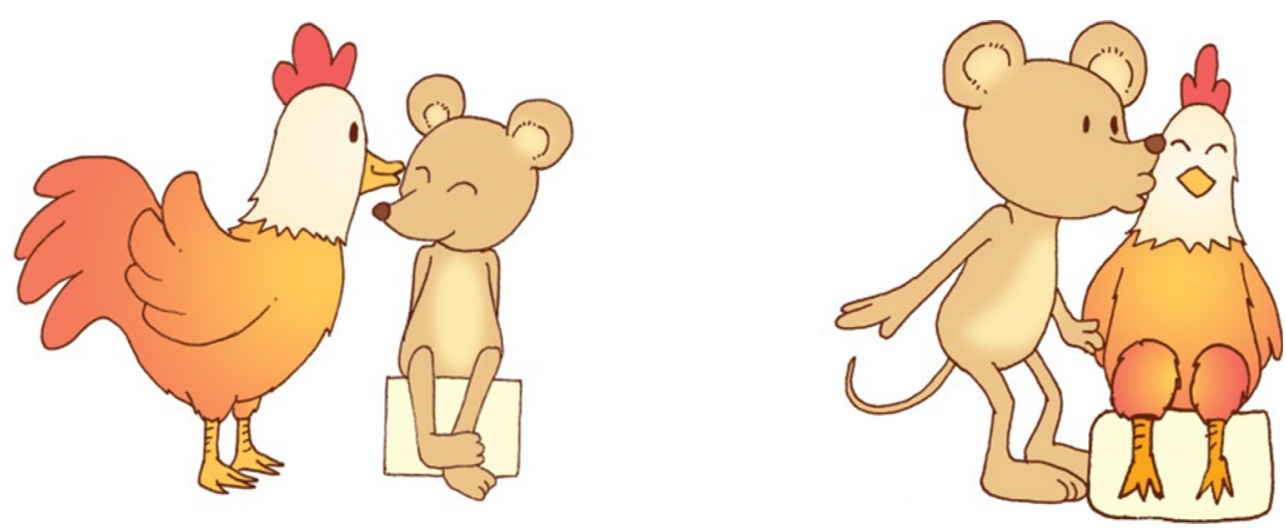

Figure 1. Example of reversible picture pair test item. 
experimental sentence, for example, which chicken is being kissed by the mouse? A trial was marked as correct if the child correctly identified the tropicalized referent (i.e., in Figure 1, the chicken in the picture on the right). Therefore, chance performance was $25 \%$ correct. The location of the correct referent was counterbalanced across lists.

\section{SL Task}

We used Arciuli and Simpson's (2011) childfriendly SL task, presented via E-Prime (Schneider, Eschman, \& Zuccolotto, 2002). The task uses the embedded triplet paradigm to assess sensitivity to adjacent dependencies in sequentially presented visual stimuli (following the use of the embedded triplet paradigm in other visual SL tasks that were designed for adults; Brady \& Oliva, 2008; Fiser \& Aslin, 2002; Turk-Browne, Jungé, \& Scholl, 2005).

The SL task comprised a familiarization phase (with a cover task) and a surprise test phase. During familiarization, participants are exposed to a stream of individually presented stimuli that contain statistical regularities (embedded triplets of images). Stimuli are cartoon-like characters that do not resemble known animals, people, or fictitious creatures-best described as "aliens." Children are told that the task is a computer game where different types of aliens are queuing to enter a spaceship.

In the familiarization phase, children saw the aliens appear on screen one at a time (each visible for $800 \mathrm{~ms}$, with 200-ms interstimulus interval). The aliens were divided into four groups of three (four base triplets), referred to as $A B C, D E F, G H I$, and $J K L$ (see the appendix in Arciuli \& Simpson, 2011). Each triplet occurred 24 times during familiarization (total of 96 presentations of the four triplets). For 6 of the 24 instances, one of the aliens was presented twice in a row. This provided the basis of the cover task: Children were required to press the space bar of the computer every time they saw the same alien appear twice in a row. The repetitions were counterbalanced among the three aliens within the triplet. For instance, for base triplet $A B C$ there were 2 occurrences of $A A B C, 2$ of $A B B C, 2$ of $A B C C$, and 18 of $A B C$. This resulted in the internal transitional probabilities of the base triplets dropping from 1.0 to 0.92 . The familiarization steam consisted of 312 individual presentations of the aliens, each appearing 26 times. The order of the triplets was randomized, with the following two constraints. Following Turk-Browne et al. (2005), no repeated triplets (i.e., no instances of $A B C A B C$ ) and no repeated pairs of triplets (e.g., $A B C D E F A B C D E F$ ) were allowed. The familiarization phase lasted $5 \mathrm{~min}$ and $12 \mathrm{~s}$.

In the surprise test phase, children's knowledge of the triplets was tested using forced choice trials. Four impossible triplets were created, each containing one alien from three different base triplets. These never occurred in the familiarization phase (AEI, $D H L, G K C$, and JBF). Thus, there was a statistical contrast between base and impossible triplets: Base triplets had high internal transitional probabilities (i.e., $B$ followed $A$ and $C$ followed $B$ with almost perfect certainty), whereas the internal probabilities of the impossible triplets were 0 . On each test trial children saw one base triplet and one impossible triplet (order of presentation counterbalanced), using the same presentation rate used during familiarization, with a 1,000-ms gap separating the base and impossible triplet. After all six aliens had been presented a new screen appeared that prompted participants to identify which of the two triplets had appeared previously in the familiarization phase, with no time constraints imposed. Each base triplet was paired with one of the impossible triplets on four separate occasions; therefore, each base triplet was seen 16 times for a total of 64 forced choice trials. The presentation of the triplet pairs was randomized for each participant. Participants' responses during the surprise test phase were tallied to provide a proportion correct score.

\section{Verbal WM}

Children's verbal WM was measured because it has been implicated in sentence comprehension (Kidd, 2013; Montgomery, Magimairaj, \& O'Malley, 2008). The Listening Span measure from Gathercole and Pickering's (2001) Working Memory Test Battery for Children was used. In the task, children read a series of sentences and are required to (a) verify the truth value of the sentence and (b) remember and recall the final word of each sentence. The test becomes progressively more difficult, as indexed by the number of sentences in each block. Gathercole and Pickering (2001) report very good test-retest reliability $(r=.83)$. The children's raw scores were used in the analyses because there are no published Australian norms for the test.

\section{Measures of General Ability}

Children's vocabulary and nonverbal IQ were measured to ensure that any relation found between SL and grammar could not be explained by general verbal or nonverbal ability. Vocabulary 
Table 1

Descriptive Statistics for Predictor Variables

\begin{tabular}{lccccc}
\hline & $M$ & $S D$ & Range & Skewness & Kurtosis \\
\hline $\mathrm{SL}^{\mathrm{a}}$ & 0.636 & 0.17 & $(0.39,0.98)$ & 0.612 & -0.952 \\
$\mathrm{WM}^{\mathrm{b}}$ & 12.66 & 2.3 & $(6,19)$ & -0.077 & 1.05 \\
Vocabulary $^{\mathrm{c}}$ & 138.26 & 16.93 & $(105,187)$ & 4.15 & 0.626 \\
Nonverbal IQ $^{\mathrm{d}}$ & 27.59 & 4.54 & $(17,35)$ & -0.169 & -0.963 \\
\hline
\end{tabular}

Note. $\mathrm{SL}=$ statistical learning; $\mathrm{WM}=$ working memory

${ }^{\text {a}} \mathrm{SL}$ task: $\min$ score $=0, \max$ score $=1$.

${ }^{\mathrm{b}} \mathrm{WM}$ task: $\min$ score $=0, \max$ score $=36$.

${ }^{\mathrm{c}}$ Vocabulary: $\min$ score $=0, \max$ score $=228$.

${ }^{\mathrm{d}}$ Nonverbal IQ: $\min$ score $=0$, $\max$ score $=36$.

was measured using the Peabody Picture Vocabulary Test, 2nd ed. (PPVT-II; Dunn \& Dunn, 2007). In the task, children are required to select the correct picture from an array of four in response to the experimenter's verbal prompt. The PPVT has excellent psychometric properties (split-half reliability, alpha, and test-retest reliability all $>$.9).

Nonverbal IQ was measured using the Raven's Coloured Progressive Matrices (RCPM; Raven, Raven, \& Court, 1998). In the task, children are presented with incomplete visual patterns and are required to complete the pattern by selecting the correct missing piece, from an array of six. Cotton et al. (2005) report good internal consistency and reliability in a large sample of Australian 6- to 11year-olds (internal consistency $[\mathrm{K}-\mathrm{R}$ formula 20] $=.89$; split-half reliability $=.90$ ). The children's raw scores for both the PPVT and the RCPM were used in the analyses because there are no published Australian norms for the tests.

\section{Results}

Table 1 shows the descriptive statistics for children's performance on the SL task, WM, vocabulary, and nonverbal ability and Table 2 shows the correlations between the measures.

Age, vocabulary, and nonverbal IQ were all significantly intercorrelated. WM and SL were significantly correlated with age (the latter consistent with Arciuli \& Simpson, 2011), although the correlations were low. Group performance on the SL task was significantly above chance, one-sample $t$ test tested against 0.5 chance performance, $t(67)=6.46$, $p<.001$, Cohen's $d=.8$.

Figure 2 shows the mean correct responses for each sentence type. The figure shows that performance on actives and subject RCs was approaching ceiling, whereas children's performance was lower
Table 2

Simple Bivariate Pearson Correlations Between Predictor Variables

\begin{tabular}{lllcc}
\hline & SL & WM & Vocabulary & Nonverbal IQ \\
\hline Age & $.263^{*}$ & $.373^{* *}$ & $.505^{* *}$ & $.291^{*}$ \\
Nonverbal IQ & .134 & .229 & $.441^{* *}$ & \\
Vocabulary & .220 & .168 & & \\
WM & .147 & & & \\
\hline
\end{tabular}

Note. $\mathrm{SL}=$ statistical learning; $\mathrm{WM}=$ working memory. $* p<.05 . * *<.01$ (two-tailed test).

and more variable on passives and object RCs. The data were modeled using generalized linear mixedeffects models (GLMMs) in $R$ using the lme 4 package (Bates \& Maechler, 2010) in $R$ (version 2.15.2; $R$ Core Team, 2012). GLMMs are a type of regression that control for participant and item variability in one model. We built separate models to predict the comprehension of each sentence type from the five predictor varables: SL, WM, vocabulary, nonverbal $\mathrm{IQ}$, and age (in months). All variables were zero centered to reduce collinearity between variables. Random intercepts for participants and items were included to account for random by-participant and by-item variation in one model (see Baayen, 2008). A binomial distribution was specified because the dependent measure was binary (i.e., correct/incorrect). Full models (i.e., all variables entered as main effects) were initially specified, and were compared against simpler models with nonsignificant predictors removed using log-likelihood comparison (using analysis of variance function in $R$ ). This process was applied iteratively until the simplest yet most explanatory model was identified. This analysis strategy allowed us to identify the most parsimonious combination of variables to explain variability in grammatical knowledge.

None of the predictor variables significantly explained variability in performance on actives and 


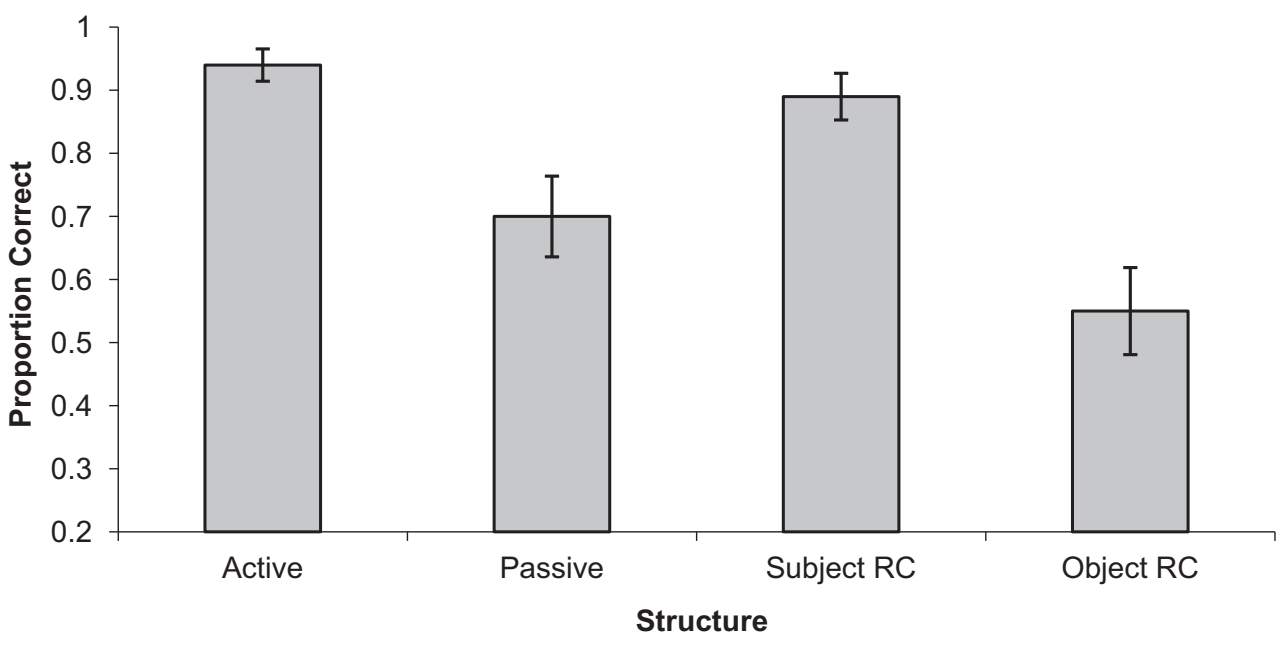

Figure 2. Mean proportion correct for each structure type (error bars denote $\pm 2 S E$ ).

subject RCs. For both actives and subject RCs, the full model containing all predictors did not differ from the null model containing only random effects, actives, $\chi^{2}(5)=3.35, p=.65$, and subject RCs, $\chi^{2}(5)=2.58, p=.76$. Therefore, none of the predictor variables were significantly related to comprehension of canonical forms. This is not surprising: Performance on these structures was good and therefore there is little variance to explain. Table 3 shows the final models for the passives and object RCs. Peformance on both passives and object RCs was significantly predicted by SL and vocabulary. The positive beta weights in both models

Table 3

Final Models Predicting Performance on Passive and Object Relative Clauses

\begin{tabular}{lcccc}
\hline & $\beta$ & $S E(\beta)$ & $z$ & $p$ \\
\hline Passive & & & & \\
$\quad$ Intercept & 1.16 & 0.18 & 6.38 & $<.001^{* * *}$ \\
SL & 2.33 & 1.06 & 2.20 & $.028^{*}$ \\
WM & 0.15 & 0.08 & 1.86 & $.063^{+}$ \\
Vocabulary & 0.023 & 0.01 & 2.07 & $.039^{*}$ \\
Object RC & & & & \\
Intercept & 0.34 & 0.14 & 2.4 & $.016^{*}$ \\
SL & 2.24 & 0.08 & 2.83 & $.005^{* *}$ \\
WM & 0.34 & 0.07 & 5.28 & $<.001^{* * *}$ \\
Vocabulary & 0.03 & 0.01 & 3.86 & $<.001^{* * *}$ \\
\hline
\end{tabular}

Note. $\quad N=68$. Passive model: $\log$ likelihood $=-292.5$, $R_{\text {GLMM }}^{2}=34.23 \%$; object RC model: log likelihood $=-319.2$, $R_{\mathrm{GLMM}}^{2}=29.06 \%$. ( $R_{\mathrm{GLMM}}^{2}$ was calculated using formulae from Nakagawa \& Schielzeth, 2013, denoting combined variance explained by fixed and random factors). SL = statistical learning; $\mathrm{WM}=$ working memory; $\mathrm{RC}=$ relative clauses.

${ }^{+} p<.10 .{ }^{*} p<.05 . * * p<.01 .{ }^{* * *} p<.001$. show that positive increases in SL and vocabulary were linked with improved comprehension of both sentence types. WM significantly and positively contributed to performance on object RCs, but was marginal for passives. Age and nonverbal IQ did not significantly contribute to model fit for either structure.

\section{Discussion}

Our hypothesis was supported: Children experienced greater difficulty and showed wider variability in comprehending passives and object RCs, and performance on these structures was significantly and independently predicted by their SL ability. The data are consistent with previous demonstrations of a significant SL-grammar link in acquisition (Conway et al., 2011; Kidd, 2012; Lany, 2014; Lum et al., 2012), and extend those data by demonstrating that the link is related to the frequency distributions of specific structures. Conway et al. (2010) suggested that superior SL abilities result in more robust representations of word order probabilities in spoken language. Since passives and object RCs are infrequent in spoken language, our data provide evidence for the hypothesis that a comparatively strong ability to detect distributional structure in our SL task is associated with more robust knowledge of infrequent structures.

An important point to consider is the underlying computational nature of the SL-grammar link. Our SL task, based on the embedded triplet paradigm, is similar to those used in word segmentation studies (e.g., Saffran et al., 1996) rather than those 
designed to test artifical grammar learning (e.g., Gómez, 2002). Theoretically, children could have discriminated between triplets and nontriplets on the basis of simple co-occurrence statistics (e.g., bigrams between individual triplet members, which are predictable in triplets but not in nontriplets). Acquisition of syntax clearly requires greater computational sophistication (e.g., Chang, Lieven, \& Tomasello, 2008). While we cannot rule out this leaner interpretation of children's performance on our SL task, we suggest that a more sophisticated computational mechanisms underlies the SL-grammar link. One possibility is that our task is tapping attention to transitional probabilities, which drive sequence learning in connectionist simple recurrent networks (Elman, 1990; Chang, Dell, \& Bock, 2006). An alternative possibility is that a kind of chunking mechanism is at play. In research with adults, Perruchet and Poulin-Charronnat (2012) demonstrated that participants extracted trisyllabic words from brief exposure and recognize them at a significantly greater rate than "part words" matched for transitional probabilities at test. They concluded that commonly co-occurring elements are extracted as chunks from the input (see also Perruchet \& PoulinCharronnat, 2015). This latter interpretation is consistent with demonstrations that 2- and 3-year-old children represent commonly occurring phrases as wholistic units (Bannard \& Matthews, 2008; Lieven, Pine, \& Baldwin, 1997).

Another important component of syntactic acquisition is the ability to make generalizations from the input. There is a lively debate in the ALL literature as to whether SL supports both the extraction of linguistic units and generalization in language acquisition (e.g., Aslin \& Newport, 2014; Perruchet, Peereman, \& Tyler, 2006) or whether it only supports extraction and a second mechanism is responsible for generalization (e.g., Bonatti, Peña, Nespor, \& Mehler, 2006; Endress \& Mehler, 2009; Thiessen, Kronstein, \& Hufnagle, 2013).

Our test of SL is a measure of extraction: Success on the task is contingent on children's ability to identify triplets from the continuous input stream. Whether or not the task indexes generalization ability is an open issue. As far as we are aware, no individual differences studies have yet attempted to link performance in SL tasks independently to extraction and generalization processes in natural language. Such research could conceiveably be conducted by teaching children novel syntactic constructions, for which there is a long history in language acquisition research (e.g., Wonnacott et al., 2012), and linking their acquisition to independent tests of SL.

A notable feature of the results is that SL was measured in the visual domain, using nonlinguistic stimuli, but still predicted syntactic knowledge. This is consistent with similar past research with both children (Conway et al., 2011; Kidd, 2012; Lum et al., 2012) and adults (Conway et al., 2010; Kaufman et al., 2010). The result suggests that the SL mechanism that supports language acquisition is domain general. While different input modalites necessarily implicate different neurological structures responsible for different types of sensory input, it has been hypothesized that there are common domain-general processing principles underlying SL across domains (Frost, Armstrong, Siegelman, \& Christiansen, 2015).

Finally, it is noteworthy that we did not observe a direct link between SL and vocabulary. We suggest that this may be a developmental effect. Although one study has found a significant association with vocabulary in elementary school-age children (Evans et al., 2009), several others, including ours, have not (Kidd \& Kirjavainen, 2011; Lum et al., 2012; Tomblin et al., 2007). The majority of significant SL-vocabulary findings have been reported in infant studies. Since multiple mechanisms support vocabulary acquisition, it is possible that SL is most strongly implicated during earlier rather than later stages of development, where other mechanisms and influences come online. For instance, once children build adequate syntactic parsing mechanisms they will be able to infer the meaning of words via processes like syntactic bootstrapping (Gleitman, 1990). Additionally, as children enter elementary school they gain increased exposure to literacy materials and begin formal literacy instruction, both of which significantly correlate with vocabulary knowledge (Cunningham \& Stanovich, 1991; Sénéchal \& LeFevre, 2002).

\section{Conclusion}

The results of the current study show that SL is implicated in individual differences in the acquisition of specific grammatical structures in 6- to 8year-old children. There is much debate regarding the degree to which grammatical acquisition is supported by domain-general or domain-specific learning mechanisms (e.g., Ambridge \& Lieven, 2011; Perruchet \& Poulin-Charronnat, 2015). The current data suggest that a domain-general capacity for SL likely plays some role in acquisition. A clear limitation of our study is that it is 
correlational; there is an urgent need for longitudinal data in this field of research (Arciuli \& von Koss Torkildsen, 2012).

\section{References}

Ambridge, B., \& Lieven, E. V. M. (2011). Child language acquisition: Contrasting theoretical approaches. Cambridge, UK: Cambridge University Press.

Arciuli, J., \& Simpson, I. C. (2011). Statistical learning in typically developing children: The role of age and speed of stimulus presentation. Developmental Science, 14, 464-473. doi:10.1111/j.1467-7687.2009.00937.x

Arciuli, J., \& Simpson, I. C. (2012). Statistical learning is related to reading ability in children and adults. Cognitive Science, 36, 286-304. doi:10.1111/j.1551-6709.2011. 01200.x

Arciuli, J., \& von Koss Torkildsen, J. (2012). Advancing our understanding of the link between statistical learning and language acquisition: The need for longitudinal data. Frontiers in Psychology, 3, 1-9. doi:10.3389/ fpsyg.2012.00324

Aslin, R. N., \& Newport, E. L. (2014). Distributional language learning: Mechanisms and models of category formation. Language Learning, 64, 86-105. doi:10.1111/ lang.12074

Baayen, R. H. (2008). Analyzing linguistic data. A practical introduction to statistics using $R$. Cambridge, UK: Cambridge University Press.

Bannard, C., \& Matthews, D. E. (2008). Stored word sequences in language learning: The effect of familiarity on children's repetition of four-word combinations. Psychological Science, 19, 241-248. doi:10.1111/j.1467-9280. 2008.02075.x

Bates, D., \& Maechler, M. (2010). Matrix: Sparse and dense matrix classes and methods. R package version 0.99937539. Retrieved from http://CRAN. R-project. org/package $=$ Matrix

Bonatti, L. L., Peña, M., Nespor, M., \& Mehler, J. (2006). How to hit Scylla without avoiding Charybdis: Comment on Perruchet, Tyler, Galland, and Peereman (2004). Journal of Experimental Psychology: General, 135, 314-321. doi:10.1037/0096-3445.135.2.314

Boyle, W., Lindell, A. K., \& Kidd, E. (2013). The role of verbal working memory in young children's sentence comprehension. Language Learning, 63, 211-242. doi:10.1111/lang.12003

Brady, T., \& Oliva, A. (2008). Statistical learning using real-world scenes. Psychological Science, 19, 678-685. doi:10.1111/j.1467-9280.2008.02142.x

Chang, F., Dell, G. S., \& Bock, J. K. (2006). Becoming syntactic. Psychological Review, 113, 234-272. doi:10.1037/ 0033-295X.113.2.234

Chang, F., Lieven, E. V. M., \& Tomasello, M. (2008). Automatic evaluation of syntactic learners in typologically different languages. Cognitive Systems Research, 9, 198213. doi:10.1016/j.cogsys.2007.10.002
Chomsky, N. (2011). Language and other cognitive systems. What is special about language? Language Learning and Development, 7, 263-278. doi:10.1080/15475441.2011.584041

Christiansen, M. H., Conway, C. M., \& Onnis, L. (2012). Similar neural correlates for language and sequential learning: Evidence from event-related potentials. Language and Cognitive Processes, 27, 231-256. doi:10.1080/ 01690965.2011.606666

Conway, C. M., Bauernschmidt, A., Huang, S. S., \& Pisoni, D. B. (2010). Implicit statistical learning in language processing: Word predictability is the key. Cognition, 114, 356-371. doi:10.1016/j.cognition.2009. 10.009

Conway, C. M., Pisoni, D. B., Anaya, E. M., Karpicke, J., \& Henning, S. C. (2011). Implicit sequence learning in deaf children with cochlear implants. Developmental Science, 14, 69-82. doi:10.1111/j.1467-7687.2010.00960.x

Cotton, S., Kiely, P., Crewther, D., Thompson, B., Laycock, R., \& Crewther, S. (2005). A normative reliability study for the Raven's Coloured Progressive Matrices for elementary school aged children from Victoria, Australia. Personality and Individual Differences, 39, 647-659. doi:10.1016/j.paid.2005.02.015

Cunningham, A. E., \& Stanovich, K. E. (1991). Tracking the unique effects of print exposure in children: Associations with vocabulary, general knowledge, and spelling. Journal of Educational Psychology, 83, 264-274. http:/ /dx.doi.org/10.1037/0022-0663.83.2.264

Diessel, H., \& Tomasello, M. (2000). The development of relative clauses in spontaneous child speech. Cognitive Linguistics, 11, 131-151. doi:10.1515/cogl.2001.006

Dunn, D. M., \& Dunn, L. M. (2007). Peabody Picture Vocabulary Test (4th ed.). Minneapolis, MN: Pearson.

Ellis, E., Robledo, M., \& Deák, G. O. (2014). Contingency learning in infancy and its relation to later vocabulary. Language Learning and Development, 10, 36-50. doi:10.1080/15475441.2013.799988

Elman, J. (1990). Finding structure in time. Cognitive Science, 14, 179-211. doi:10.1207/s15516709cog1402_1

Endress, A. D., \& Mehler, J. (2009). Primitive computations in speech processing. Quarterly Journal of Experimental Psychology, 62, 2187-2209. doi:10.1080/17470210902783646

Evans, J., Saffran, J. R., \& Robe-Torres, K. (2009). Statistical learning in children with specific language impairments. Journal of Speech, Language, and Hearing Research, 52, 321-335. doi:10.1044/1092-4388(2009/07-0189

Fiser, J., \& Aslin, R. (2002). Statistical learning of higherorder temporal structure from visual shape sequences. Journal of Experimental Psychology: Learning, Memory, and Cognition, 28, 458-467. doi:10.1037//0278-7393.28.3.458

Frost, R., Armstrong, B. C., Siegelman, N., \& Christiansen, M. H. (2015). Domain-generality versus modality specificity: The paradox of statistical learning. Trends in Cognitive Sciences, 19, 117-125. doi:10.1016/ j.tics.2014.12.010

Gathercole, S., \& Pickering, S. (2001). Working Memory Test Battery for Children (WMTB-C). Sydney, Australia: Pearson Assessment. 
Gertner, Y., Fisher, C., \& Eisengart, J. (2006). Learning words and rules: Abstract knowledge of word order in early sentence comprehension. Psychological Science, 17, 684-691. doi:10.1111/j.1467-9280.2006.01767.x

Gleitman, L. (1990). The structural sources of verb meaning. Language Acquisition, 1, 3-55. doi:10.1207/ s15327817la0101_2

Gómez, R. (2002). Variability and detection of invariant structure. Psychological Science, 13, 431-436. doi: 10.1111/1467-9280.00476

Hay, J. F., Pelucchi, B., Graf Estes, K., \& Saffran, J. R. (2011). Linking sounds to meaning: Infant statistical learning in a natural language. Cognitive Psychology, 63, 93-106. doi:10.1016/j.cogpsych.2011.06.002

Kaufman, S. B., DeYoung, C. G., Gray, J. R., Jimenez, L., Brown, J., \& Mackintosh, N. (2010). Implicit learning as an ability. Cognition, 116, 321-340. doi:10.1016/j.cognition.2010.05.011

Kidd, E. (2012). Implicit statistical learning is directly associated with the acquisition of syntax. Developmental Psychology, 48, 171-184. doi:10.1037/a0025405

Kidd, E. (2013). The role of verbal working memory in children's sentence comprehension: A critical review. Topics in Language Disorders, 33, 208-223. doi:10.1097/ TLD.0b013e31829d623e

Kidd, E., Brandt, S., Lieven, E., \& Tomasello, M. (2007). Object relatives made easy: A crosslinguistic comparison of the constraints influencing young children's processing of relative clauses. Language and Cognitive Processes, 22, 860-897. doi:10.1080/01690960601155284

Kidd, E., \& Kirjavainen, M. (2011). Investigating the contribution of procedural and declarative memory to the acquisition of past tense morphology: Evidence from Finnish. Language and Cognitive Processes, 26, 794-829. doi:10.1080/01690965.2010.493735

Lany, J. (2014). Judging words by their cover and the company they keep: Probabilistic cues support word learning. Child Development, 85, 1727-1739. doi:10.1111/ cdev.12199

Lany, J., \& Saffran, J. R. (2010). Infants' acquisition of lexical categories. Psychological Science, 21, 284-291. doi:10. $1177 / 0956797609358570$

Lieven, E., Pine, J., \& Baldwin, G. (1997). Lexically-based learning and the development of grammar in early multi-word speech. Journal of Child Language, 24, 187-219. doi: 10.1017/S0305000996002930

Lum, J. A. G., Conti-Ramsden, G., Page, D., \& Ullman, T. (2012). Working, declarative and procedural memory in specific language impairment. Cortex, 48, 1138-1154. doi:10.1016/j.cortex.2011.06.001

Misyak, J., \& Christiansen, M. H. (2012). Statistical learning and language: An individual differences study. Language Learning, 62, 302-331. doi:10.1111/j.1467-9922. 2010.00626.x

Misyak, J. B., Christiansen, M. H., \& Tomblin, J. B. (2010). On-line individual differences in statistical learning predict language processing. Frontiers in Psychology, 1. doi:10.3389/fpsyg.2010.00031
Montgomery, J., Magimairaj, B., \& O’Malley, M. (2008). The role of working memory in typically developing children's complex sentence comprehension. Journal of Psycholinguistic Research, 37, 331-354. doi:10.1007/ s10936-008-9077-z

Nakagawa, S., \& Schielzeth, H. (2013). A general and simple method for obtaining $R^{2}$ from generalized linear mixed-effects models. Methods in Ecology and Evolution, 4, 133-142. doi:10.1111/j.2041-210x.2012. 00261.x

Newport, E. L. (2011). The modularity issue in language acquisition: A rapprochement? Comments on Gallistel and Chomsky. Language Learning and Development, 7, 279-286. doi:10.1080/15475441.2011.605309

Perruchet, P., Peereman, R., \& Tyler, M. D. (2006). Do we need algebraic-like computations? A reply to Bonatti, Peña, Nespor, and Mehler (2006). Journal of Experimental Psychology: General, 135, 322-326. doi:doi.org/10.1037/ 0096-3445.135.2.322

Perruchet, P., \& Poulin-Charronnat, B. (2012). Beyond transitional probability computations: Extracting wordlike units when only statistical information is available. Journal of Memory and Language, 66, 807-818. doi:10.1016/j.jml.2012.02.010

Perruchet, P., \& Poulin-Charronnat, B. (2015). The learnability of language: Insights from the implicit learning literature. In P. Rebuschat (Ed.), Implicit and explicit learning of languages (pp. 137-163). Amsterdam, Netherlands: John Benjamins.

R Core Team. (2012). R: A language and environment for statistical computing. Vienna, Austria: $\mathrm{R}$ Foundation for Statistical Computing. Retrieved from http://www. R-project.org

Raven, J., Raven, J. C., \& Court, J. H. (1998). Manual for the Raven's Progressive Matrices and Vocabulary Scales. Great Britain, UK: Oxford Psychologist Press.

Romberg, A. R., \& Saffran, J. R. (2010). Statistical learning and language acquisition. Wiley Interdisciplinary Reviews in Cognitive Science, 1, 906-914. doi:10.1002/wcs.78

Saffran, J. R., Aslin, R. N., \& Newport, E. L. (1996). Statistical learning by 8-month-old infants. Science, 274, 1926-1928. doi:10.1126/science.274.5294.1926

Schneider, W., Eschman, A., \& Zuccolotto, A. (2002). EPrime reference guide. Pittsburgh, PA: Psychology Software Tools.

Sénéchal, M., \& LeFevre, J. (2002). Parental involvement in the development of children's reading skill: A fiveyear longitudinal study. Child Development, 73, 445-460. doi:10.1111/1467-8624.00417

Shafto, C. L., Conway, C. M., Field, S. L., \& Houston, D. M. (2012). Visual sequence learning in infancy: Domain-general and domain-specific associations with language. Infancy, 17, 247-271. doi:10.1111/j.1532-7078. 2011.00085.x

Siegelman, N., \& Frost, R. (2015). Statistical learning as an individual ability: Theorotical perspectives and empirical evidence. Journal of Memory and Language, 81, 105-120. doi:10.1016/j.jml.2015.02.001 
Smith, L. B., \& Yu, C. (2008). Infants rapidly learn wordreferent mappings via cross-situational statistics. Cognition, 106, 1558-1568. doi:10.1016/j.cognition.2007.06.010

Spencer, M., Kaschak, M. P., Jones, J. L., \& Lonigan, C. J. (2015). Statistical learning is related to early literacy-related skills. Reading and Writing, 28, 467-490. doi:10.1007/ s11145-014-9533-0

Thiessen, E. D., Kronstein, A. T., \& Hufnagle, D. G. (2013). The extraction and integration framework: A two process account of statistical learning. Psychological Bulletin, 139, 792-814. doi:10.1037/a0030801

Tomblin, J. B., Mainela-Arnold, E., \& Zhang, X. (2007). Procedural learning in adolescents with and without specific language impairment. Language Learning and Development, 3, 269-293. doi:10.1080/15475440701377477

Turk-Browne, N. B., Jungé, J. A., \& Scholl, B. J. (2005). The automaticity of visual statistical learning. Journal of Experimental Psychology: General, 134, 552-564. doi:10. 1037/0096-3445.134.4.552

Wonnacott, E. (2011). Balancing generalization and lexical conservatism: An artificial language study with child learners. Journal of Memory and Language, 65, 1-14. doi:10.1016/j.jml.2011.03.001

Wonnacott, E., Boyd, J. K., Thomson, J., \& Goldberg, A. E. (2012). Input effects on the acquisition of a novel phrasal construction in 5 year olds. Journal of Memory and Language, 66, 458-478. doi:10.1016/j.jml. 2011.11.004

Xiao, R., McEnery, T., \& Qian, Y. (2006). Passive constructions in English and Chinese: A corpus-based contrastive study. Languages in Contrast, 6, 109-149. doi:10.1075/ lic.6.1.05xia

\section{Supporting Information}

Additional supporting information may be found in the online version of this article at the publisher's website:

Appendix S1. Test Sentence Lists 